\title{
In vitro virulence of three Lecanicillium lecanii strains against the whitefly, Bemisia tabaci (Genn.) (Hemiptera: Aleyrodidae)
}

\author{
Yusuf Ali Abdulle ${ }^{1 * \dagger}$, Talha Nazir ${ }^{1 \dagger}$, Azhar Uddin Keerio ${ }^{1}$, Habib Ali², Shah Zaman ${ }^{3}$, Tauqir Anwar ${ }^{4}$, \\ Trinh Duy Nam ${ }^{1}$ and Dewen Qiu ${ }^{1 *}$
}

\begin{abstract}
Background: Whitefly, Bemisia tabaci (Genn.) (Hemiptera: Aleyrodidae), is one of the most harmful pests in greenhouses and in open fields.

Main body: The present study aimed to assess in vitro virulence of 3 entomopathogenic fungal strains (EPFs) of Lecanicillium lecanii 3 (V-3), 4 (V-4), and 5 (V-5) against the whitefly, Bemisia tabaci (Genn.) (Hemiptera: Aleyrodidae), by spray method. The 3 disparate bioassays were performed encompassed of conidial concentrations and fungal filtrate of the strains, $V-3, V-4$, and $V-5$, and also their binary combinations. In the filtrate bioassay, $2 \mathrm{ml}$ of fungal filtrate of each strain was used. In the conidial bioassay, 3 disparate concentrations $\left(1 \times 10^{5}, 1 \times 10^{6}\right.$, and $1 \times 10^{7}$ conidia $\left.\mathrm{ml}^{-1}\right)$ were used for each fungal strain, while in the binary combinations $(1 \mathrm{ml}$ filtrate $+1 \mathrm{ml}$ conidia) of $\mathrm{V}$ - 3 $\times V-3, V-4 \times V-4$, and V-5 $\times$ V-5 were used. Mortality rates against the whitefly were recorded on the 7 th day. In the conidial bioassay, maximum mortality rates were found at V-3 strain (90.6\%), V-4 strain (78.4\%), and V-5 strain $(83.6 \%)$ at the highest concentration $\left(1 \times 10^{7}\right.$ conidia $\left.\mathrm{ml}^{-1}\right)$ on the 7 th day. In the filtrate bioassay, $\mathrm{V}-3$ strain revealed a maximum mortality (93\%), V-4 strain (85\%), and then V-5 strain (87\%) on the 7 th day. Moreover, in the bioassay of binary combinations, the highest mortality rate of the whitefly was counted in $\mathrm{V}-3 \times \mathrm{V}-3$ strain (84.6\%), V-4 $\times$ V-4 strain (70.6\%), and V-5 $\times$ V-5 strain (79.8\%) on the 7th day.
\end{abstract}

Conclusion: All treatments had the potential to control B. tabaci significantly. In all bioassays, the $V-3$ strain was the extreme virulent, and the filtrate application of $\mathrm{V}-3$ strain was the utmost impressive against $B$. tabaci.

Keywords: Entomopathogenic fungi, Virulence, Lecanicillium lecanii, Bemisia tabaci, Biological control

\section{Background}

Whitefly, Bemisia tabaci (Genn.) (Hemiptera: Aleyrodidae), is one of the most serious pests of crops that causes great losses (Oliveira et al. 2001). It causes direct destruction by sucking the plant sap, and also indirect destruction by encouraging the growth of black sooty mold on their honeydew secretions (Varma and Malathi

\footnotetext{
*Correspondence: idaajaa236@gmail.com; qiudewen@caas.cn

${ }^{\dagger}$ Yusuf Ali Abdulle and Talha Nazir contributed equally to this work.

'State Key Laboratory for Biology of Plant Diseases and Insect Pests, Institute of Plant Protection, Chinese Academy of Agricultural Sciences, Beijing 100081, People's Republic of China

Full list of author information is available at the end of the article
}

2003). It causes economic losses in many crops, including leafy vegetables, cotton, beans, and tomatoes (Fontes et al. 2012). The application of chemical pesticides leads to increase resistance and has a negative environmental impact that encourages the development of alternative pest management strategies, where microbial control plays a key role (Nazir et al. 2019b). Application of microbial control agents mainly entomopathogenic fungi isolates (EPFs) has been examined to control various orchard and field crop pests (Lacey and Shapiro-Ilan 2008). The use of EPFs in biological control is developing extremely due to food safety concerns, environmental awareness, and the failure of conventional chemicals 
(Shahid et al. 2012). EPF can play a significant role in biocontrol programs because of their pathogenic pathways, their wide range of hosts, and the control of economic insect pests such as the sucking insects (thrips, mites, aphids whiteflies, and mealybugs) (Khan et al. 2012). The use of biological control for pest control in greenhouses has been proven to be effective, and its application worldwide is growing steadily (Perdikis et al. 2008). The most promising EPF include Lecanicillium lecanii, Metarhizium anisopliae, and Beauveria bassiana (Saleh et al. 2016). L. lecanii is widely distributed and can cause a large-scale epizootic in tropical and subtropical regions as well as in humid and warm environments (del Prado et al. 2008). When the fungal conidia encounter the host, they attach to the epidermis through a hydrophobic mechanism and germinate under favorable conditions to form the germ tube (Inglis and Goettel 2001). During this process, the fungus produces several infection specific structures, including penetration pegs or appressoria, enabling the developing hyphae to enter the host integument (Ortiz-Urquiza and Keyhani 2013). L. lecanii has been documented to infect B. tabaci (Zhu and Kim 2011) causing a good mortality (Xie et al. 2019).

The present study was undertaken to evaluate the bioefficacy of $L$. lecanii strains against $B$. tabaci under laboratory conditions.

\section{Main text}

\section{Materials and methods}

\section{Insect rearing}

Adults of the whitefly, B. tabaci were collected from Langfang station, the research area of Institute of Plant Protection (IPP), Chinese Academy of Agricultural Sciences (CAAS), Beijing, China. The pest was reared on cotton plants under a controlled greenhouse at $25 \pm$ $2{ }^{\circ} \mathrm{C}, 65 \%$ RH with a $14: 10$ (L:D) photoperiod.

\section{Fungal culture and conidia suspension}

The L. lecanii strains, V3, V4, and V5, were obtained from the key laboratory of Biopesticides Engineering, Department of Bio-Pesticides and Biocontrol, Institute of Plant Protection (IPP), Chinese Academy of Agricultural Sciences (CAAS). The strains were obtained from infected B. tabaci. The strains were grown on Potatoes Dextrose Agar in Petri dishes for 20 days at $25^{\circ} \mathrm{C}$. Conidia were harvested after 21 days. The Petri dishes were flashed $20 \mathrm{ml}$ with sterile water and filtered by using a sterile cheese cloth. Three different concentrations of conidia $\left(1 \times 10^{5}, 1 \times 10^{6}\right.$, and $\left.1 \times 10^{7}\right)$ of spore suspension were determined using a hemocytometer. Earlier performing bioassays against $B$. tabaci, the viability test of conidia was accomplished, according to the procedures of (Hywel-Jones and Gillespie 1990).

\section{Fungal filtrate}

To get fungal filtrates, $4 \mathrm{ml}$ of conidial suspension was prepared in $100 \mathrm{ml}$ of Adamek liquid medium of all fungal strains. The culture was incubated 3 days in the dark for $150 \mathrm{rpm}$ at $25^{\circ} \mathrm{C}$. Secondary culture was prepared and added to $3 \mathrm{ml}$ of primary culture in to Adamek liquid medium and incubated 7 days in the dark for 150 $\mathrm{rpm}$ at $25^{\circ} \mathrm{C}$. The fungal filtrate was centrifuged $20 \mathrm{~min}$, $11,000 \mathrm{rpm}$ at $4{ }^{\circ} \mathrm{C}$. The supernatant was filtered $0.45 \mu \mathrm{m}$ pore size filter.

\section{Pathogenicity test}

The effects of the fungal conidia, filtrate, and binary combinations ((filtrate + conidia) on the cotton whitefly were tested under laboratory conditions using a manual sprayer. Three different conidia concentrations $\left(1 \times 10^{5}\right.$, $1 \times 10^{6}$, and $1 \times 10^{7}$ ) were tested. Filtrate bioassays were evaluated by applying 7 days fungal filtrate. Binary combinations ( $1 \mathrm{ml}$ conidia $+1 \mathrm{ml}$ filtrate) were estimated, while sterilized water was used as a control. For this

Table 1 Factorial analysis of variance of the mortality rate of Bemisia tabaci bioassay with the conidia of the three Lecanicillium lecanii strains

\begin{tabular}{|c|c|c|c|c|c|}
\hline Source & DF & SS & MS & $F$ value & $p$ value \\
\hline Concentration & 3 & 78,385 & $26,128.2$ & 399.41 & $\leq 0.001$ \\
\hline Time & 3 & 58,315 & $19,438.2$ & 297.14 & $\leq 0.001$ \\
\hline Treatment & 2 & 693 & 346.7 & 5.30 & $<0.058$ \\
\hline Concentration $\times$ time & 9 & 9667 & 1074.1 & 16.42 & $\leq 0.001$ \\
\hline Concentration $\times$ treatment & 6 & 807 & 134.4 & 2.06 & 0.060 \\
\hline Time $\times$ treatment & 6 & 497 & 82.8 & 1.27 & 0.275 \\
\hline Concentration $\times$ time $\times$ treatment & 18 & 577 & 32.0 & 0.49 & 0.960 \\
\hline Error & 192 & 12,560 & 65.4 & & \\
\hline Total & 239 & 161500 & & & \\
\hline $\mathrm{CV} / \mathrm{GM}$ & & $19.59 / 41.29$ & & & \\
\hline
\end{tabular}

DF Degree of freedom, SS Sum of squares, MS Mean sum of squares, F F-statistic, CV Coefficient of variation, GM Grand mean

${ }^{*} p<0.001$ (highly significant) and $p<0.05$ (significant); three-way factorial analysis of variance (ANOVA) at $a=0.05$ 


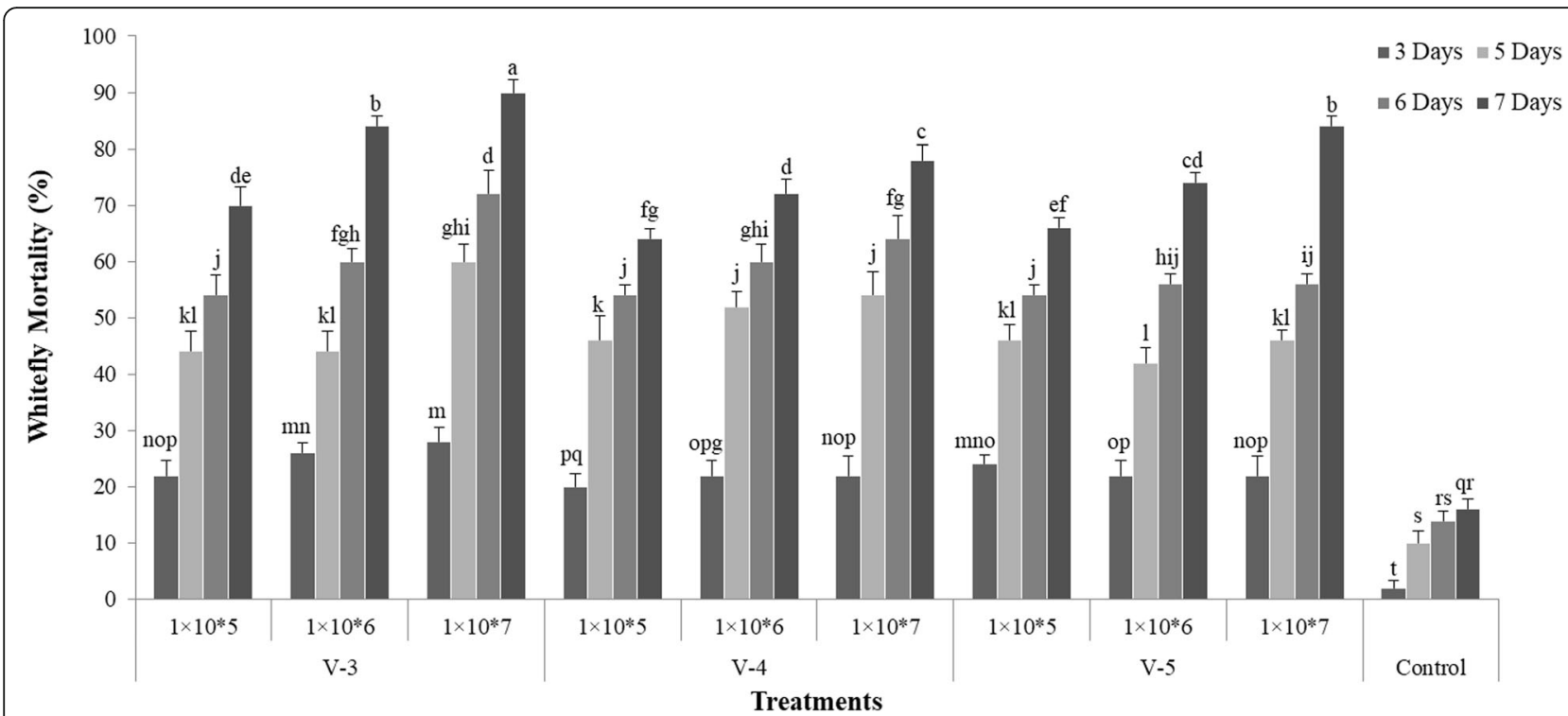

Fig. 1 Mean mortality (\%) of Bemisia tabaci noted at different time intervals (3rd, 5th, 6th, and 7th) for conidial bioassays executed with different strains of Lecanicillium lecanii $(\mathrm{V}-3, \mathrm{~V}-4$, and $\mathrm{V}-5)$ at three conidial concentrations (i.e., $1 \times 10^{5}, 1 \times 10^{6}$, and $1 \times 10^{7} \mathrm{conidia} \mathrm{ml}^{-1}$ ) of each fungal strain and one control. The columns show mean percent mortality \pm SE $(n=5)$. Treatment columns bearing different alphabets are significantly different from other treatments (LSD test at $p=0.05$ ). See Table 1

purpose, 10 adults of whitefly were placed in a Petri dish for each treatment having fresh cotton leaves and incubated at $25 \pm 2{ }^{\circ} \mathrm{C} 65 \% \mathrm{RH}$. Whitefly mortality rate was recorded on 3rd, 5th, 6th, and 7th day. Each treatment had 5 replications.

$$
\text { Mortality percentage }=\frac{\text { Dead whiteflies }(\text { B.tabaci }) \times 100}{\text { Total whiteflies }(\text { B.tabaci })}
$$

\section{Statistical analysis}

Virulence of the 3 stains of L. lecanii as conidia, filtrate, and binary combination were analyzed, using factorial analysis of variance (ANOVA) Statistix software (Version 8.1) (Tallahassee, FL). Comparison of the treatment means was performed using Fischer's least significant difference (LSD) test at $\alpha=0.05$ ).

\section{Results and discussion \\ Pathogenicity test of conidia}

To evaluate the mortality of $B$. tabaci, 3 concentrations $\left(1 \times 10^{5}, 1 \times 10^{6}\right.$, and $\left.1 \times 10^{7}\right)$ of strains of L. lecanii were tested under laboratory conditions. The factorial analysis of variance exhibited significant impact of disparate concentrations, disparate intervals of time, and their interaction on the mean whitefly mortality rates $(F$ $=399.41, p \leq 0.001 ; F=297.14, p \leq 0.001$; and $F=$ 16.42, $p \leq 0.001$, respectively (Table 1)). Strain V-3 of $L$. lecanii caused a significant mortality rate of whitefly at all the concentrations than the control. Nonetheless, the maximum mortality $(90.6 \%)$ was noted at 7 th day at a concentration of $1 \times 10^{7}$ conidia $\mathrm{ml}^{-1}$. The minimum mortality $(69.4 \%)$ was found at 7 th day at a concentration of $1 \times 10^{5}$ conidia $\mathrm{ml}^{-1}$ (Fig. 1). Toxicity of L. lecanii strain $\mathrm{V}-5$ against $B$. tabaci showed akin trend such as in the V-3. Maximum mortality rate $(83.6 \%)$ of whitefly was witnessed after the 7 th day at the concentration of $1 \times 10^{7}$ conidia $\mathrm{ml}^{-1}$ (Fig. 1 ). The minimum mortality $(65.2 \%)$ was reported at a concentration of $1 \times 10^{5} \mathrm{co}-$ nidia $\mathrm{ml}^{-1}$ (Fig. 1). The highest mortality rate $(78.4 \%)$ of $L$. lecanii strain V-4 against B. tabaci was recorded at the highest concentration $\left(1 \times 10^{7}\right.$ conidia $\left.\mathrm{ml}^{-1}\right)$, while the minimum mortality of whitefly (64\%) was witnessed at the concentration of $1 \times 10^{5}$ conidia $\mathrm{ml}^{-1}$ at 7 th day (Fig. 1). Mean whitefly mortality in the control Petri dishes was $16.2 \%$.

Table 2 Factorial analysis of variance of mortality of Bemisia tabaci bioassayed with the filtrates of the three Lecanicillium lecanii strains

\begin{tabular}{llllll}
\hline Source & DF & SS & MS & F value & $\boldsymbol{p}$ value \\
\hline Treatments & 3 & $39,533.8$ & $13,177.9$ & 266.89 & $\leq 0.001$ \\
Time & 3 & $25,113.7$ & 8371.2 & 169.54 & $\leq 0.001$ \\
Treatments $\times$ time & 9 & 5131.2 & 570.1 & 11.55 & $\leq 0.001$ \\
Error & 64 & 3160.0 & 49.4 & & \\
Total & 79 & $72,938.7$ & & & \\
CV/GM & & $15.32 / 45.88$ & & & \\
\hline
\end{tabular}

DF Degree of freedom, SS Sum of squares, MS Mean sum of squares, $F$ Fstatistic, CV Coefficient of variation, GM Grand mean

${ }^{*} p<0.001$ (highly significant) and $p<0.05$ (significant); two-way factorial analysis of variance (ANOVA) at $a=0.05$ 


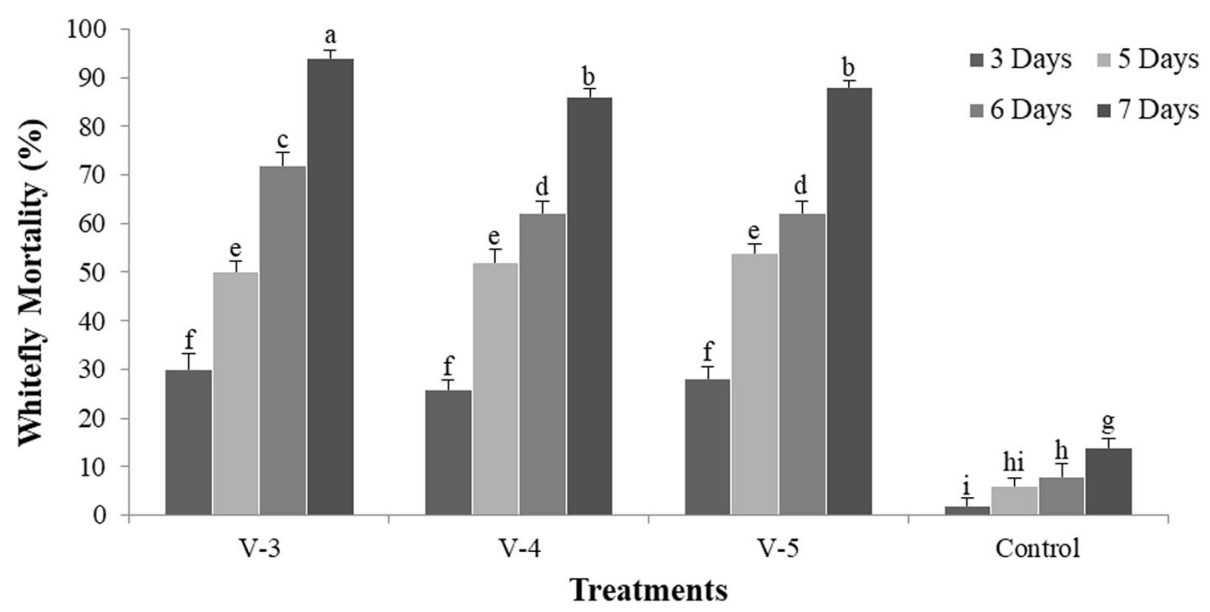

Fig. 2 Mean mortality (\%) of Bemisia tabaci noted at different time intervals (3rd, 5th, 6th, and 7th) for filtrate bioassays executed with different strains of Lecanicillium lecanii $(V-3, V-4$, and $V-5)$. The columns show mean percent mortality $\pm S E(n=5)$. Treatment columns bearing different alphabets are significantly different from other treatments (least significant difference (LSD test at $p=0.05$ ). See Table 2

\section{Filtrate bioassay}

Outcomes of the filtrate bioassay showed that overall average mortality of the whitefly through the tested strains of fungus was more than the treatments of conidia. Filtrates of fungus, observation, and their interactions on B. tabaci mortality had a significant impact (Table 2 ). The maximum mortality (93\%) was noted on the 7th day of treatment of $(\mathrm{V}-3)$ and the minimum mortality (85\%) was noted on the 7 th day through the application of filtrate of V-4. Filtrate of fungal strain $\mathrm{V}-5$ revealed an average whitefly mortality rate of $87 \%$ (Fig. 2).

\section{Binary combination (conidia + filtrate) virulence}

The pathogenicity bioassays executed by the binary combinations (conidia + filtrate) of three strains of fungus had a significant impact of all the treatments, observation time, and their interactions on whitefly mortality (Table 3). Significant and maximum whitefly mortality (84.6\%) was witnessed at $\mathrm{V}-3 \times \mathrm{V}-3$, while the minimum mortality rate of whitefly $(70.6 \%)$ was noted at the combination of $\mathrm{V}-4 \times \mathrm{V}-4$ on the 7 th day of treatment. Binary combination of V-5 $\times \mathrm{V}-5$ affected $(79.8 \%)$ whitefly mortality on the 7th day of treatment (Fig. 3).

Generally, the study outcomes are in line with the earlier studies describing the efficiency of disparate isolates of L. lecanii and Beauveria bassiana against the sucking insect pests (Hesketh et al. 2008).

In all the bioassays, the mortality rate of $B$. tabaci was reliant on concentration and time, and it increased through increasing the conidia concentration and time interval after the application. The mortality of 90.6, 78.4, and $83.6 \%$ was reported after 7 days of conidial application of $\mathrm{V}-3, \mathrm{~V}-4$, and $\mathrm{V}-5$ at the highest concentration $1 \times 10^{7}$ conidia $\mathrm{ml}^{-1}$ whereas 93,85 , and $87 \%$ mortality rate was recorded after 7 days of filtrate application of V-3, V-4, and V-5 strains. One more experiment was executed and stated $84.6,70.6$, and $79.8 \%$ mortality of B. tabaci after 7 days by binary combination (conidia + filtrate) of $\mathrm{V}-3 \times \mathrm{V}-3, \mathrm{~V}-4 \times \mathrm{V}-4$, and $\mathrm{V}-5 \times \mathrm{V}-5$ fungal strains. Obtained results are in line with (Halimona and Jankevica 2011) who verified several concentrations of five EPFs against $A$. fabae and M. fuscoviride and found that the highest concentration $1 \times 10^{8} \mathrm{ml}^{-1}$ of conidia exhibited the maximum mortality after 7 days. Also, the results are in accordance with (Hanan et al. 2020b) who demonstrated that in all the bioassays, L. lecanii V-3 strain was the utmost pernicious and application of its filtrate was found to be the utmost efficient against green peach aphid Myzus persicae (Sulz.) (Nazir et al. 2019a).

Table 3 Factorial analysis of variance of mortality of Bemisia tabaci bioassayed with the binary combinations (conidia + filtrate) of the three Lecanicillium lecanii strains

\begin{tabular}{llllll}
\hline Source & DF & SS & MS & $\boldsymbol{F}$ value & $\boldsymbol{p}$ value \\
\hline Treatments & 3 & $26,973.7$ & 8991.25 & 128.45 & $\leq 0.001$ \\
Time & 3 & $26,033.7$ & 8677.92 & 123.97 & $\leq 0.001$ \\
Treatments $\times$ time & 9 & 4651.2 & 516.81 & 7.38 & $\leq 0.001$ \\
Error & 64 & 4480.0 & 70.00 & & \\
Total & 79 & $62,138.7$ & & & \\
CV/GM & & $19.86 / 42.13$ & & & \\
\hline
\end{tabular}

$D F$ Degree of freedom, SS Sum of squares, MS Mean sum of squares, $F$ statistic, $C V$ Coefficient of variation, GM Grand mean

${ }^{*} p<0.001$ (highly significant) and $p<0.05$ (significant); two-way factorial analysis of variance (ANOVA) at $\alpha=0.05$ 


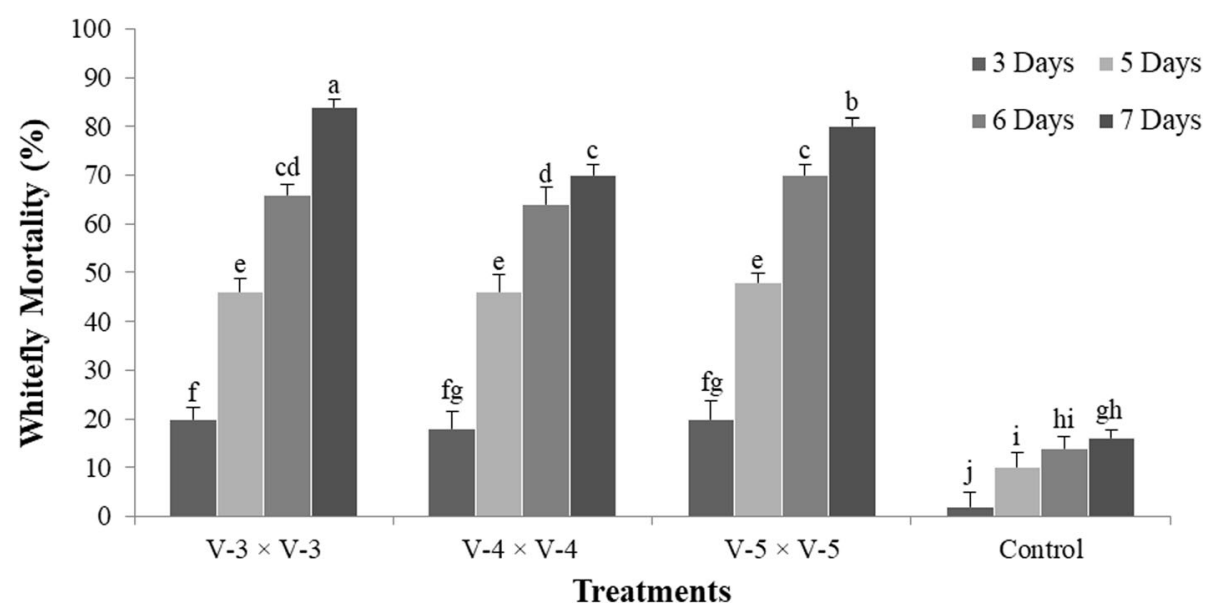

Fig. 3 Mean mortality (\%) of Bemisia tabaci noted at different time intervals (3rd, 5th, 6th, and 7th) for bioassays executed with the binary combinations of different strains of Lecanicillium lecanii. Treatments included the combination of V-3 $\times \mathrm{V}-3, \mathrm{~V}-4 \times \mathrm{V}-4$, and $\mathrm{V}-5 \times \mathrm{V}-5$, and control. The columns shows mean percent mortality \pm SE $(n=5)$. Treatment columns bearing different alphabets are significantly different from other treatments (LSD test at $p=0.05$ ). See Table 3

Mortality percentage of $B$. tabaci affected with the conidial concentration, exposure time and temperature (Keerio et al. 2020). Similarly, Wright et al. (2005) also confirmed that the aphids mortality increased through an increase of the concentration of conidia and time interval. The $V$. lecanii revealed maximum mortality in initial stages and minimum mortality in the older instars of B. tabaci (Zaki 1998). EPF demonstrated a worthy control of whitefly (Abdel-Raheem et al. 2016). The application of filtrate was more efficient than the application of conidia chiefly in the insects having a short life cycle to control the insect pests. There could be a possible reason for this that the conidia attachment to the cuticle of insects is less effective than the enormous penetration of the filtrates (Hanan et al. 2020a).

Regarding combined applications, acquired results were similar to Yun et al. (2017) who revealed the dual action of EPF, M. anisopliae, B. bassiana, and Botrytis cinerea against $M$. persicae, and observed that the practice of filtrate by blastospores presented the extreme mortality of $M$. persicae. The binary combination (conidia + filtrate) provided the lowest mortality rate as compared to the application of filtrate. Thus, it is clear that the application of fungal filtrate had the utmost virulence efficiency.

\section{Conclusions}

The in vitro study revealed the competence of 3 strains of L. lecanii against B. tabaci. V-4 exhibited the lowest mortality rate than the other both strains (V-3 and V-5), either alone or in the binary combinations (conidia + filtrate) of identical strain. The filtrate application was extremely suitable material to control the whitefly. Binary combination of conidia + filtrate had some of the invincible effect and cannot be used efficiently to control whitefly. However, the most characterization of L. lecanii strains (V-3, V-4 and V-5) and their prospective functional insecticidal elicitors is required to better clarify their approach of action.

\section{Abbreviations}

PDA: Potato dextrose agar; L:D: Light:dark

\section{Acknowledgements}

The authors thank the China Scholarship Council (CSC) and Graduate School of Chinese Academy of Agricultural Sciences (GSCAAS) for providing a Ph.D. scholarship.

\section{Authors' contributions}

Conceptualization: YAA, TN, and DQ. Data curation: YAA and TN. Formal analysis: TN, HA, and TA. Funding acquisition: DQ. Investigation: YAA, TN, and TDN. Methodology: YAA and AUK. Project administration: DQ. Resources: DQ Software: YAA, TN, and SZ. Supervision: DQ. Validation: TN and AUK. Writing - original draft: YAA and AUK. Writing - review and editing: TN, HA, SZ, and DQ. The authors read and approved the final manuscript.

\section{Funding}

Not applicable.

\section{Availability of data and materials}

All data and materials are mentioned in the manuscript.

Ethics approval and consent to participate

Not applicable.

\section{Consent for publication}

Not applicable.

\section{Competing interests}

The authors declare that they have no competing interests.

\section{Author details}

${ }^{1}$ State Key Laboratory for Biology of Plant Diseases and Insect Pests, Institute of Plant Protection, Chinese Academy of Agricultural Sciences, Beijing 100081, People's Republic of China. 'Department of Agricultural Engineering, 
Khawaja Fareed University of Engineering and Information Technology, Rahim Yar Khan, Punjab 64200, Pakistan. ${ }^{3}$ Department of Entomology, University of Agriculture, Faisalabad, Punjab 38000, Pakistan. ${ }^{4}$ Pest Warning \& Quality Control of Pesticides, Punjab Agriculture Department, Sillanwali, Punjab 40010, Pakistan.

Received: 1 May 2020 Accepted: 5 October 2020

Published online: 15 October 2020

\section{References}

Abdel-Raheem MA, Reyad NF, Abdel-Rahman IE, Al-Shuraym L (2016) Evaluation of some isolates of entomopathogenic fungi on some insect pests infesting potato crop in Egypt. Int J Chem Tech Res 9:479-485

del Prado EN, lannacone J, Gómez H (2008) Effect of two entomopathogenic fungi in controlling Aleurodicus cocois (Curtis, 1846)(Hemiptera: Aleyrodidae). Chil J Agric Res 68:21-30

Fontes F von HM, Colombo CA, Lourenção AL (2012) Structure of genetic diversity of Bemisia tabaci (Genn.)(Hemiptera: Aleyrodidae) populations in Brazilian crops and locations. Sci Agric 69:47-53.

Halimona J, Jankevica L (2011) The influence of Entomophthorales isolates on aphids Aphis fabae and Metopeurum fuscoviride. Latv Entomol 50:55-60

Hanan A, Basit A, Nazir T et al (2020a) Anti-insect activity of a partially purified protein derived from the entomopathogenic fungus Lecanicillium lecanii (Zimmermann) and its putative role in a tomato defense mechanism against green peach aphid. J Invertebr Pathol 170:107282

Hanan A, Nazir T, Basit A et al (2020b) Potential of Lecanicillium lecanii (Zimm.) as a microbial control agent for green peach aphid, Myzus persicae (Sulzer) (Hemiptera: Aphididae). Pak J Zool 52:131

Hesketh H, Alderson PG, Pye BJ, Pell JK (2008) The development and multiple uses of a standardised bioassay method to select hypocrealean fungi for biological control of aphids. Biol Control 46:242-255

Hywel-Jones NL, Gillespie AT (1990) Effect of temperature on spore germination in Metarhizium anisopliae and Beauveria bassiana. Mycol Res 94:389-392

Inglis GD, Goettel MS (2001) Use of Hyphomycetous fungi for managing insect pests. In: Butt TM, Jackson CY, Magan N (eds) Fungi as biocontrol agents: progress, problems and potential

Keerio AU, Nazir T, Abdulle YA et al (2020) In vitro pathogenicity of the fungi Beauveria bassiana and Lecanicillium lecanii at different temperatures against the whitefly, Bemisia tabaci (Genn.)(Hemiptera: Aleyrodidae). Egypt J Biol Pest Control 30:1-9

Khan S, Guo L, Maimaiti Y et al (2012) Entomopathogenic fungi as microbial biocontrol agent. Mol Plant Breed 3:63-79

Lacey LA, Shapiro-llan DI (2008) Microbial control of insect pests in temperate orchard systems: potential for incorporation into IPM. Annu Rev Entomol 53: 121-144

Nazir T, Basit A, Hanan A et al (2019a) In vitro pathogenicity of some Entomopathogenic fungal strains against green peach aphid Myzus persicae (Homoptera: Aphididae). Agronomy 9:7

Nazir T, Khan S, Qiu D (2019b) Biological control of insect pest. In: Pests-insects, management, control. IntechOpen https://doi.org/10.5772/intechopen.81431

Oliveira MRV, Henneberry TJ e, Anderson P (2001) History, current status, and collaborative research projects for Bemisia tabaci. Crop Prot 20:709-723

Ortiz-Urquiza A, Keyhani N (2013) Action on the surface: entomopathogenic fungi versus the insect cuticle. Insects 4:357-374

Perdikis D, Kapaxidi E, Papadoulis G (2008) Biological control of insect and mite pests in greenhouse solanaceous crops. Eur J Plant Sci Biotechnol 2:125-144

Saleh MME, Abdel-Raheem MA, Ebadah IM, Huda HE (2016) Natural abundance of entomopathogenic fungi in fruit orchards and their virulence against Galleria mellonella larvae. Egypt J Biol Pest Control 26:203

Shahid AA, Rao QA, Bakhsh A, Husnain T (2012) Entomopathogenic fungi as biological controllers: new insights into their virulence and pathogenicity. Arch Biol Sci 64:21-42

Varma A, Malathi VG (2003) Emerging geminivirus problems: a serious threat to crop production. Ann Appl Biol 142:145-164

Wright MS, Raina AK, Lax AR (2005) A strain of the fungus Metarhizium anisopliae for controlling subterranean termites. J Econ Entomol 98:1451-1458

Xie T, Jiang L, Li J et al (2019) Effects of Lecanicillium lecanii strain JMC-01 on the physiology, biochemistry, and mortality of Bemisia tabaci Q-biotype nymphs. PeerJ 7:e7690
Yun H-G, Kim D-J, Gwak W-S et al (2017) Entomopathogenic fungi as dual control agents against both the pest Myzus persicae and phytopathogen Botrytis cinerea. Mycobiology 45:192-198

Zaki FN (1998) Efficiency of the entomopathogenic fungus, Beauveria bassiana (Bals), against Aphis crassivora Koch and Bemesia tabaci, Gennandius. J Appl Entomol 122:397-399

Zhu H, Kim JJ (2011) Susceptibility of the tobacco whitefly, Bemisia tabaci (Hemiptera: Aleyrodidae) biotype Q to entomopathogenic fungi. Biocontrol Sci Tech 21:1471-1483

\section{Publisher's Note}

Springer Nature remains neutral with regard to jurisdictional claims in published maps and institutional affiliations.

\section{Submit your manuscript to a SpringerOpen ${ }^{\circ}$ journal and benefit from:}

- Convenient online submission

- Rigorous peer review

- Open access: articles freely available online

- High visibility within the field

- Retaining the copyright to your article

Submit your next manuscript at $\boldsymbol{\nabla}$ springeropen.com 